\title{
Lucano y Estacio en la Comedia de Dante
}

\section{Ángel García Galiano}

\section{OpenEdition}

\section{Journals}

Edición electrónica

URL: https://journals.openedition.org/cher/2615

DOI: $10.4000 /$ cher.2615

ISSN: 2803-5992

\section{Editor}

Presses universitaires de Strasbourg

\section{Edición impresa}

Fecha de publicación: 27 junio 2017

Paginación: 47-54

ISBN: 978-2-86820-961-0

ISSN: 1968-035X

\section{Referencia electrónica}

Ángel García Galiano, «Lucano y Estacio en la Comedia de Dante», reCHERches [En línea], 18 | 2017, Publicado el 01 diciembre 2021, consultado el 15 diciembre 2021. URL: http:// journals.openedition.org/cher/2615 ; DOl: https://doi.org/10.4000/cher.2615

\section{(ब) $(0 \odot$}

Ce(tte) œuvre est mise à disposition selon les termes de la Licence Creative Commons Attribution Pas d'Utilisation Commerciale - Partage dans les Mêmes Conditions 4.0 International. 


\title{
Lucano y Estacio en la Comedia de Dante
}

\author{
Ángel García Galiano*
}

Lo buon maestro cominciò a dire: «Mira colui con quella spada in mano, che vien dinanzi ai tre sì come sire: quelli è Omero poeta sovrano; l'altro è Orazio satiro che vene; Ovidio è 'l terzo, e l'ultimo Lucano.

Però che ciascun meco si convene nel nome che sonò la voce sola, fannomi onore, e di ciò fanno bene'. (INF, IV, 85-93)

Homero, Horacio, Ovidio y Lucano. Estamos en el limbo, un lugar de dolor sin tormento, alejados de Dios aunque exentos de las penas corporales del infierno. Dante inquiere a su maestro por la causa que los obliga a estar allí y él responde:

estos no pecaron; y si hicieron méritos, no les basta, porque no fueron bautizados, y como vivieron antes del cristianismo, no adoraron a Dios adecuadamente: como estos soy yo mismo. Por tales defectos, no por otro malvado, estamos perdidos y atormentados sólo porque vivimos en deseo sin esperanza. Un gran dolor me oprimió el corazón cuando lo oí, porque supe que gente de mucha valía estaba en suspenso en aquel limbo. (INF, IV, 34-45)

Así, con una honda congoja en el corazón, Dante se acerca a los pies de un hermoso castillo circundado por un foso, a este lado una cohorte de almas los esperan para honrarles y darles la bienvenida, para celebrar el regreso de su admirado poeta Virgilio.

Lo asombroso comienza ahora, cuando los más grandes poetas de la historia se arraciman en un abrazo y

* Profesor contratado doctor de Teoría de la Literatura en la misma Universidad Complutense de Madrid.

1 «El buen maestro empezó a decir:

- Mira aquel que viene con una espada en la mano delante de los otros tres como el rey, ése es Homero, poeta soberano; el otro que viene es el satírico Horacio, el tercero es Ovidio y el último Lucano. Porque coinciden conmigo en el nombre que hizo sonar la voz sola, me honran y hacen bien.» (INF, IV, 85-93) 
cuando hubieron charlado un rato juntos se volvieron a mí con un gesto amistoso y mi maestro sonrió. Y aún me hicieron más honor, ya que me incorporaron a su grupo, de tal modo que fui el sexto entre tanta sabiduría. Así anduvimos hasta la luz, hablando de cosas de las que es mejor callar como era hermoso entonces el hablar allí donde estábamos. (INF, IV, 97-105)

Los cinco grandes poetas de la clasicidad consagran con su gesto amistoso a Dante y lo reciben como el sexto del grupo. Imagino que si no fuera por la alta y difícil misión que tiene que cumplir, el poeta toscano ya se debería sentir más que pagado con esta suerte de coronación simbólica en el Olimpo de la literatura. Seguramente por eso, con una mezcla de mal disimulada vanidad y extraño pudor, se niega a relatarnos los pormenores de su conversación con tamaños escritores: si entonces era hermoso hablar, ahora lo es el callar. Dante, con elegante superioridad y legítimo orgullo, nos escamotea uno de los momentos cumbres de su viaje, aunque le honra regalarnos este verso memorable: «así anduvimos hasta la luz» (INF, IV, 103).

Caminar no solo hacia la luz, sino hasta la luz, como metáfora que revele el sentido último de toda poesía, escribir como fulgor instantáneo y eterno que proclama la belleza absoluta de las cosas, expresión del anhelo por abrir espacios de luminosidad en medio de la tiniebla, escribir como acto de iluminación, aun en medio de la más oscura y tenebrosa caverna, pues hasta en ella, como nos recuerda Platón, y ahora Dante, fulge una antorcha, la poesía, que nos recuerda y señala el camino ascendente de regreso hasta la Luz. Aunque para eso, como veremos enseguida en el caso de Lucano, haya que ir, y así nos lo confirma y atestigua Virgilio, hasta el centro mismo helado del Infierno, allí donde la luz, literalmente, se ha congelado.

Hay una última característica del poeta que Virgilio expone a Dante:

Però che ciascun meco si convene

nel nome che sonò la voce sola,

fannomi onore, e di ciò fanno bene. (INF, IV, 91-93)

"Porque coinciden conmigo en el nombre que hizo sonar la voz sola», y es que en eso, en poetizar, en hacer sonar la voz sola, coinciden conmigo (y contigo); le dice Virgilio a su discípulo. Verso memorable en que se declara, acaso por primera vez, la conocida y honda sentencia que reconoce el acto de escribir como una acción intransitiva: poeta es quien proclama su voz en solitario, es el que eleva su palabra al aire de su vuelo, pero no para comunicar algo concreto a alguien concreto, ya que el artista no mira al utilizar el lenguaje su lado más práctico, o concreto comunicativo, sino que se adentra en su polisémica faceta expresiva, simbólica; poeta es quien hace sonar la voz a solas para que en ese decir sin interlocución concreta (y por tanto caduca) la palabra recobre su sentido originario y brille por primera vez.

Bella y solitaria labor, pues, la del poeta, y a nosotros se nos antoja que esta gavilla de versos camino del castillo hasta la luz contienen todo un manifiesto poético preñado de fulguraciones. 
Homero, Ovidio, Horacio y Lucano, el extraordinario poeta estoico nacido en Córdoba, autor de la Farsalia, muerto a los 26 años por orden de Nerón. Vamos ahora a detenernos brevemente para consignar la relación que la Comedia establece entre Dante y Lucano, y lo primero que observamos es que el canto VI de su Farsalia sirve a Dante de modelo explícito a la hora de trabar la arquitectura simbólica de uno de los cantos más extraordinarios, y complejos, de la Comedia, me refiero al canto IX del Infierno:

El poeta y su mentor han atravesado la laguna estigia pero no pueden abrir las puertas de la amurallada ciudad de Dite. Virgilio intenta tranquilizar a Dante y le relata lo siguiente:

Raramente sucede que alguno de nosotros haga el camino por el que yo voy. Es verdad que estuve aquí abajo otra vez, conjurado por aquella fiera Eritón que quería devolver las almas a sus cuerpos. Poco hacía que me había despojado de la carne cuando ella me hizo entrar en esa muralla para sacar un espíritu del círculo de Judas. Ese es el lugar más bajo, el más oscuro y el más lejano del cielo que gira con todo el universo. Conozco bien el camino, así que estáte tranquilo. Este pantano que despide tan gran hedor rodea la ciudad dolorosa donde no podemos ahora entrar sin violencia. (INF, IX, 19-33)

La fiera Eritón, la bruja de Tesalia que, tal y como nos narra Lucano en acaso sus más impactantes hexámetros ${ }^{2}$, hizo retornar el alma al cuerpo de un soldado muerto para que le predijera a Sexto Pompeyo el derrotero que tomaría la inminente batalla da título al poema. Lo sorprendente es que Virgilio se erija en protagonista de la empresa al ser interpelado por la bruja para descender hasta el helado Cocito, hasta el círculo de Judas, esto es, de los traidores, y sacar de allá al espíritu que abría de profetizar la derrota de Pompeyo. La enciclopedia dantiana nos explica que si el recurso al personaje lucaniano de la maga, le servía a Dante para crear un precedente al descenso de Virgilio a los infiernos, la invención del descenso se lo podría haber sugerido una circunstancia análoga narrada en Eneida VI 562-566³ , en donde la Sibila que guía a Eneas le relata cómo ella ya había descendido anteriormente al Hades en compañía de Hécate. Constatamos así la necesidad, para ascender hasta la luz, salir de la caverna, de, antes, haber tocado y abrazado el mismo fondo los ínferos, lección de sabiduría que preside implícitamente el relato virgiliano. De este modo se crea un triple y especular homenaje, de Dante a Lucano y de Lucano a Virgilio mediante el cual se identifica y asocia simbólicamente a Virgilio con la Sibila y a Dante con Eneas, además de celebrar y reconocer explícitamente, como en tantas otras ocasiones, al poeta cordobés y su trunco poema.

2 Farsalia, VI, vv. 507-827 (Lucano 2001).

3 La adivina comenzó a hablar así: «¡Afamado caudillo de los teucros, le está vedado al puro de corazón poner pie en este umbral del crimen! Pero a mí cuando me confió Hécate la custodia del bosque del Averno me instruyó en los castigos impuestos por los dioses y me guio en persona por todo este recinto.» (Virgilio 2000) 
En efecto, las referencias a temas y personajes del poeta cordobés, además del citado, aparecen en momentos especialmente significativos del poema. Pensemos en el caso de Catón, apenas amanecidos en las playas que conducen a la montaña del Purgatorio (canto I del Purgatorio), o las alusiones a su ejército en desbandada por el desierto de Libia (cantos XIV y XXV del Infierno), las referencias a Julio César (Purgatorio, IX y Paraíso, VIㄴ) o la final tragedia de Pompeyo traicionado por Ptolomeo (también canto VI del Paraíso ${ }^{5}$ ), episodios y personajes de la Farsalia, que pespuntean el relato dantiano y generan un horizonte de lectura en el que brilla con luz propia la admiración de Dante hacia Lucano.

No podemos saber de qué habló Dante con sus admirados maestros, porque el poeta ha decidido escamotearnos ese exquisito y peripatético coloquio, pero de una cosa estamos seguros, de que Dante echó de menos a alguien en aquella escueta compaña, alguien que habría sido el séptimo en concordia, él incluido, pues acaban de aceptarlo en tan riguroso canon. Nos referimos, por supuesto, a su admirado Estacio, discípulo de Virgilio y autor de la Tebaida, una de las fuentes más requeridas por el toscano a lo largo de este periplo cultural que, entre otras cosas, significa la Comedia.

Pero Dante nos tiene preparada una extraña sorpresa, pues no ha querido que el autor de la Tebaida sobreviva sin esperanza en el limbo de los no bautizados y le tiene destinado un lugar en el paraíso. ¿Cómo es ello posible tratándose de un poeta pagano? Veámoslo.

Estamos en el Purgatorio, cantos XX a XXII, se trata de uno de los momentos más extraordinarios de este increíble viaje; Dante y Virgilio ascienden trabajosamente por un estrecho sendero, ultimando la cornisa de los avariciosos,

4 «Luego, cerca del tiempo en que el cielo quiso serenar al mundo a su manera, César lo tomó por voluntad de Roma», (PAR, VI, 55-57). Lucano en su Farsalia cuenta que fue el pueblo el que dio a César el nombre de emperador y le permitió asumir todo el poder. Dante subraya con intención este episodio porque siempre consideró a Julio César el fundador del imperio.

5 En donde resume luego las campañas de César contra Pompeyo: «lo que hizo después que salió salió de Ravenna y saltó el Rubicón fue de tal vuelo que no podría seguirlo ni la lengua ni la pluma. Volvió su ejército hacia España, luego a Durazzo y golpeó Farsalia de tal modo que se sintió el dolor hasta en el cálido Nilo. Volvió a ver Antandro y Simeonta, de donde salió y donde yace Héctor, y luego volvió a levantar el vuelo para mal de Tolomeo. Desde allí bajó como un rayo sobre Juba desde donde se volvió a vuestro occidente donde oía la tuba pompeyana. Lo que hizo con el siguiente portador lo ladra Bruto con Casio en el infierno, y Módena y Perusa se dolieron. Llora todavía la desgraciada Cleopatra que, huyendo ante ella, tomó de la culebra una muerte súbita y terrible. Corrió con aquél hasta el litoral rojo, con aquél puso tanta paz en el mundo que cerraron las puertas a Jano.» (PAR, VI, 61-81) En efecto, después de la aplastante victoria de Farsalia, Pompeyo intentó refugiarse en Egipto (por eso habla del caliente Nilo) junto a Ptolomeo, aliado de Roma, que lo mandó matar para congraciarse así con César. 
cuando oí, como algo que cae, temblar el monte, por lo que me quedé tan helado como suele quedarse el que se encamina a la muerte. Ciertamente no se agitó $\tan$ fuertemente Delos antes de que Latona hiciese en ella el nido para parir los dos ojos del cielo. Luego empezó por todas partes un grito tal que el maestro se volvió hacia mí diciendo: «No temas mientras yo te guíe». Todos decían Gloria in excelsis Deo, por lo que entendí a los cercanos, a los que se podía entender lo que gritaban.

Nosotros estábamos inmóviles y en suspenso, como los pastores que oyeron ese canto los primeros, hasta que cesó el temblor y se acabó el canto. (PUR, XX, 127-141)

En efecto, de súbito la montaña tiembla, los viajeros se asustan, entonces aparece una sombra en el camino que los saluda amablemente y les explica que el terremoto es un buen augurio, significa que un alma se ha liberado de sus pecados temporales y se prepara para ascender hasta la gloria, él mismo. Virgilio le pregunta quién es y Estacio, que no reconoce al venerado maestro, relata cómo fue poeta en la corte imperial, escribió, siguiendo el modelo de la Eneida, la Tebaida y dejó sin terminar la Aquileida. Se reconoce natural de Tolosa, error absurdo en Dante que conoce bien al poeta y sus orígenes eleáticos. Luego trataré de interpretarlo. Estacio, aun ignorante de quién es su interlocutor, continúa explicando su vocación poética y su devoción absoluta por el maestro Virgilio:

A mi ardor sirvieron de semilla las chispas que me abrasaron en la divina llama con la que se han iluminado más de mil. Hablo de la Eneida, que me fue madre y nodriza en poesía. Sin ella no hubiera escrito ni el peso de un dracma. Y por haber vivido allí cuando vivió Virgilio consentiría un sol más de lo que debo para mi salida del exilio. (PUR, XXI, 94-102)

Virgilio se conmueve ante esta afirmación extrema de su discípulo, hubiera dado por bueno un año más (un sol) de suplicio en la montaña purificatoria con tal de haber vivido en el siglo de su maestro ${ }^{6}$. Es una intensa declaración de amor a Virgilio que Dante cuida mucho de poner en boca de alguien a quien él admira profundamente. Pero lo mejor de todo es el sentido de la composición de la escena, pues tal y cómo nos viene presentada, terremoto, encuentro, anagnósisis, lo que se está sugiriendo, creo, es que el mejor premio a su salvación que Estacio va a recibir es esta milagrosa posibilidad de conocer en persona a su maestro.

Si observamos ahora en los versos de la Comedia la cantidad de homenajes, préstamos y citas que remiten a versos o temas extraídos de la Tebaida, seguramente tras Ovidio y el propio Virgilio, el autor clásico más citado o aludido por Dante, concluiremos que este encuentro entre maestro y discípulo, atestiguado por el propio Dante, posee un marcado carácter simbólico.

En efecto, la gozosa salvación de Estacio ha provocado en la montaña sagrada el temblor de su propio anhelo ascensional, tal y como lo explica el propio poeta:

Tiembla cuando algún alma se siente limpia de tal modo que se levanta o se mueve para subir y ese grito acompaña al temblor. La prueba de la purificación

6 ¿Desafiando incluso la posibilidad de haberse salvado y habitar ahora, junto al maestro, en la oquedad sin esperanza del limbo? 
es el querer subir que, ahora libre de cambiar de comunidad, sorprende al alma y ese querer la alegra. (PUR, XXI, 58-63) 7

Es decir, la alegría del alma, dentro, y su ansia por subir se verifica fuera como gozo y temblor de la montaña entera. Y el encuentro entre ambos poetas, como apuntaba, no significa otra cosa sino un anticipo del propio cielo que le aguarda. Dante no puede contener el deseo de revelar al poeta de Elea su admirable y quasi celestial reunión y proclama: «Este que guía mis ojos hacia lo alto es aquel Virgilio del que tú tomaste la fuerza de cantar a los hombres y a los dioses.» (PUR, XXI, 124-126) En cierto sentido es una declaración de mutuo discipulazgo, ya que si a Dante lo conduce hacia lo alto, fue Virgilio quien propició con sus versos la «insólita» conversión de Estacio al cristianismo.

Ante esta desmesurada y laica epifanía poética, Estacio no puede sino hincarse de hinojos para ir a besar las plantas de su amado maestro, el cual le reconviene y le recuerda que ambos son solo sombras; ante lo cual, el dichoso autor de la Tebaida proclama:

-Ahora puedes comprender la cantidad del amor que arde en mí por ti, que olvido nuestra vacuidad y trato a las sombras como algo sólido. (PUR, XXI, 133-6136)

Versos admirables que dan fin a este estremecedor canto XXI.

En el canto siguiente prosigue la maravillosa conversación entre ambos, Estacio confiesa que le debe a Virgilio la vocación de poeta y la fe, esto es, la salvación eterna:

-Primero tú me enviaste hacia el Parnaso, a beber en sus grutas, y fuiste el primero que me iluminaste hacia Dios. Hiciste como el que camina de noche y lleva luz tras de sí, que no le sirve a él pero ilumina a las personas que van tras él, cuando dijiste «El siglo se renueva; vuelve la justicia y el primer tiempo humano, una nueva progenie baja del cielo». Por ti fui poeta y por ti fui cristiano. (PUR, XXII, 64-73.)

Si en el limbo de los sabios paganos ya vimos que la poesía era, simbólica y literalmente, un caminar hasta la luz, el poeta bautizado y converso nos reconfirma ahora esta misma idea poniendo de ejemplo al más grande de todos, el maestro común de Estacio y Dante: él fue quien lo iluminó con sus versos, en concreto y sobre todo con aquella Bucólica IV en que, según la creencia general de la Edad Media, Virgilio habría profetizado el nacimiento de Cristo y la nueva edad de oro de la salvación. «Por ti fui poeta y por ti fui cristiano». Y lo hace con un símil extraordinario: como el que camina de noche y lleva una luz tras de sí, que a él no ha de servirle, pero que a los que le siguen ilumina el camino seguro.

7 «Tremaci quando alcuna anima monda sentesi, sì che surga o che si mova per salir su; e tal grido seconda.

de la mondizia sol voler fa prova, che, tutta libera a mutar convento, l'alma sorprende, e di voler le giova.» (PUR, XXI, 58-63) 
Recuérdese que según celebrado epíteto del filósofo Juan de Salisbury, Virgilio era conocido en su siglo no por ser el autor de la Eneida, ni siquiera por ser poeta, sino por ser Magus, esto es 'adivino', al proclamar en sus cantos la venida del Mesías. De hecho, en la celebración navideña del nacimiento de Cristo en Mantua, patria del poeta, se le incluía con toda naturalidad durante la misa en la nómina de profetas veterotestamentarios que habían vaticinado el nacimiento del salvador.

Entonces confiesa emocionado Estacio que gracias a esos versos suyos secundó las predicaciones de los cristianos, ahora sometidos a dura persecución por Domiciano y que «antes de que yo condujese a los griegos a los ríos de Tebas con mi poesía, recibí el bautismo, pero fui cristiano oculto por miedo, aparentando paganismo durante mucho tiempo» (PUR, XXII, 88-90). Ese talante pusilánime, por miedo al martirio, que le obligó a ocultar su fe fue la causa de que haya pasado tantos centenares de años en la montaña del Purgatorio.

Dante les sigue, a la zaga, admirado del intenso diálogo entre ambos y confiesa:

Ellos iban delante y yo solito detrás, y escuchaba sus discursos que me iluminaban para poetizar. (PUR, XXII, 127-129)

Y si bien es cierto que nos escamoteara en el limbo su dichosa conversación con los demás poetas, ahora Dante ha sido muy generoso al constatar notarialmente el diálogo extraordinario que se ha resuelto entre Virgilio y su admirado y agradecido discípulo, el cual, una vez termina de contar la historia de su conversión inquiere al maestro por otros afamados poetas latinos, como Terencio, Plauto o Varrón, y Virgilio le confirma que habitan con él en el limbo, con lo que se cierra una nómina poética que comenzara en el canto IV del Infierno, y mediante la cual, el Dante escritor, agudísimo en el sentido de la composición de la Comedia, enlaza aquel momento inicial de su peregrinación con este del encuentro con el poeta que nos faltaba y al que ha decidido, iluminado por Virgilio, enviarlo hacia lo alto. No insisto más en la intensificación del campo asociativo de la luz que acompaña en los versos de Dante a toda esta escena.

Apuntaré, en cambio, una breve coda sobre el «error» de Dante al atribuirle a Estacio un origen tolosano y la insólita decisión de convertirlo en cristiano escondido por temor a las persecuciones. Resulta cuando menos sorprendente que pueda cometer un error tan de bulto si por debajo no late alguna finalidad secreta o escondida ${ }^{8}$. Tolosa, la denominación occitana y albigense de la actual Toulouse, representa histórica y simbólicamente a toda esa comunidad cátara arrasada en Provenza por la cruzada de Inocencio III y el rey de Francia, en colosal persecución aniquiladora de los cristianos puros, o cátaros, que

8 «Vosotros, que tenéis la inteligencia sana, mirad bien la doctrina que se esconde bajo el velo de los versos extraños» (INF, IX, vv. 61-63) 
poblaban aquellas tierras con su talante pacífico, vegetariano y renunciante, honda provocación evangélica ante la prepotente jerarquía de la Iglesia católica, al rechazar la mediación sacramental de sus sacerdotes, abogar por una religiosidad interior y fomentar el encuentro directo con el Espíritu a través del consolament, o consolamentum. Mucho se ha escrito ya sobre la posible relación entre el catarismo, la poesía trovadoresca y el dolce stil nuovo, sobre todo su posible influencia en la ideología de los fedeli d'amore ${ }^{9}$.

En ese sentido, puede no ser muy descabellado sugerir, tal y como apunta Maria Soresina (2009) en su documentado trabajo, que la presencia del recién purificado Estacio no signifique solo el reconocimiento al poeta admirado por Dante, al que remite y homenajea constantemente en su poema, encuentro que, en realidad, como acabamos de ver, es una ofrenda de amor y poesía a Virgilio, maestro común, al que ambos deben su estro y salvación, camino de la luz; la presencia insólita de Estacio podría también, tácitamente, sugerir y representar, en tanto que tolosano espurio y cristiano clandestino por temor a las persecuciones, a todos esos poetas provenzales que secundaron la herejía gnóstica y que hubieron de callar o esconder su mensaje de luz en una oscura retórica de hermetismo solo cómplice, evidente y precisa para los iniciados, a la manera en que el propio Dante sin empacho alguno nos refiere tantas veces en las interpretaciones a sus propios versos de la Vita nova que estos solo podrán ser enteramente comprendidos por los fedeli d'amore.

Concluyamos. Si con Lucano Virgilio primero y ahora Dante, con nosotros, se sirvió de la bruja de Tesalia para descender hasta los confines mismos del infierno, con Estacio, gracias de nuevo al poeta de Mantua, vamos a emprender, arrebatados de amor, el definitivo viaje hasta la luz.

Vale.

\section{Bibliografía}

Alighieri, D., La Divina Commedia <http://divinacommedia.weebly.com/>

Alighieri, D., 2012, La Divina Comedia, trad. de Violeta Díaz Corralejo, Madrid, Sial.

Lucano, 2001, Farsalia, trad. Antonio Hogado Redondo, Madrid, Gredos.

Rougemont (de) D., 1979, El amor y occidente, Barcelona, Kairos.

Soresina M., 2009, Libertà vo cercando. Dante e il catarismo, Bergamo, Moretti

\& Vitali Editori.

Virgilio, 2000, Eneida, trad. de Javier Echave Susaeta, Madrid, Gredos.

9 Frente a la Iglesia de Roma, ellos hablaban de la Iglesia del Amor, como provocador palíndromo. Tanto Denis de Rougemont (1979) en su monumental El amor y occidente como Maria Soresina (2009) apuntan con tino a elucidar las relaciones entre el poeta y la «herejía» gnóstica del siglo xiII. 